\title{
HISTOLOGICAL AND IMMUNOLOGICAL STUDIES ON THE PROTECTIVE EFFECT OF EUCALYPTUS CAMALDULENSIS AGAINST ROUNDUP-INDUCED HEPATOTOXICITY IN FROGS
}

\author{
AWADALLA EA ${ }^{1}$, MOHAMED AAA ${ }^{2}$, ABDELSADIK A ${ }^{1 *}$ \\ ${ }^{1}$ Department of Zoology, Faculty of Science, Aswan University, Aswan 81528, Egypt. ${ }^{2}$ Department of Botany, Faculty of Science, Aswan \\ University, Aswan 81528, Egypt. Email: aabdelsadik@aswu.edu.eg
}

Received: 25 January 2019, Revised and Accepted: 20 February 2019

\section{ABSTRACT}

Objective: Roundup (RUP) is a prominent utilized worldwide herbicide. Possible toxicity of RUP is a considerable debate. We studied the possible mode of RUP cytotoxicity and the antitoxic effects of Eucalyptus camaldulensis (EUC) in male of Bufo regularis.

Methods: We were analyzed EUC extract scavenging activity and determined the bioactive compounds. In addition, we measured the lipid peroxidation (LPO), histopathological changes, and gene expression in the liver. Frogs were divided into negative control, EUC, RUP, and combined RUP and EUC treated (RUP+EUC) groups. Data were represented as mean \pm SD and considered statistically significant when $\mathrm{p}<0.05$.

Results: Treatment of animals with RUP increased LPO and numerous pathological changes with an increased number of melanomacrophages (MMCs). In addition, RUP-treated group revealed downregulation of different genes associated with immunity and mitochondrial activity. On the other side, RUP+EUC-treated group showed restoration of the normal hepatic structure and ultrastructural integrity for a considerable extent. The current study evidenced immune system dysregulation through recombinant activating gene 1 downregulation and overexpression of CX chemokine receptor type- 4 and cytochrome c oxidase subunit I.

Conclusion: The current data represent a direct evidence for the toxicity of RUP that experimentally verified by the histopathological changes, elevated LPO, and imbalanced gene expression. Moreover, aggregation of MMCs pointed to the faced immunological challenges due to RUP toxicity. We are emphasizing that uncontrolled use of RUP is potentially hazardous to the living organisms and man. The application of natural antagonists such a plant extract (e.g., EUC) can reduce biological toxicity.

Keywords: Roundup, Glyphosate, Cytochrome c oxidase subunit I, Melanomacrophages, Eucalyptus camaldulensis, Egyptian frogs.

(c) 2019 The Authors. Published by Innovare Academic Sciences Pvt Ltd. This is an open access article under the CC BY license (http://creativecommons. org/licenses/by/4. 0/) DOI: http://dx.doi.org/10.22159/ajpcr.2019.v12i4.31857

\section{INTRODUCTION}

Pesticides are typically used as insecticides, algaecides, and herbicides [1]. Notably, herbicides undoubtedly provoke a substantial increase in the agriculture welfare and escalate the yield of economic crops, which lowering hunger. However, they commonly endure in the agricultural areas for prolonged periods, showing various physiological side effects to human and pets [2]. The gradual accumulation of such chemicals in the terrestrial and aquatic environment can result in adverse effects to the anuran health too [3,4]. Particularly, survival rate of modern amphibians directly influenced by herbicides suppresses their disease fighting ability and severely inhibits larval progress. As well, it changes morphology and physiology and inevitably provokes DNA mutations [5]

Glyphosate-based herbicides roundup (RUP) is the predominantly used broad-spectrum herbicides [6]. A negative impact of such hazardous chemicals is not restricted to the adjacent environment. It could improperly influence the entire biological system in a particular area. It may frequently interact with different variables such as environmental change, UV-B radiation, rising irresistible sicknesses, and alien species [7].

Plant extracts were used as competent herbicides in the past. Raw extraction of biologically active compounds from target plants facilitates pharmacological studies promptly leading to the synthesis of eco-friendly compounds [8]. Eucalyptus camaldulensis (EUC) is a widespread riparian tree of both ecological and economic importance. This Australian native aromatic tree was intentionally introduced to Egypt to stabilize the local banks of the River Nile during flooding time [9].
Most recognized species of the genus Eucalyptus are commonly used as traditional therapies for respiratory tract infections and inflammatory diseases. Furthermore, essential oils of Eucalyptus were being used appropriately as a possible alternative herbicide with minimal groundwater pollution, mammalian toxicity, and no remarkable persistence in the soil [10].

The present work was intentionally designed to characterize the possible consequences of RUP on some biochemical, histological, and immunological parameters in the liver of Bufo regularis and to assess the preventive effects of EUC extract against RUP hepatotoxicity. Moreover, now, herbal medicine is widely used in different aspects of fitness and wound healing. We utilized EUC here as antitoxic extract that modulates and boosts the immune system.

\section{MATERIALS AND METHODS}

\section{Chemicals}

The herbicide used in this study was a commercial formulation RUP containing $48 \%(\mathrm{w} / \mathrm{v})$ isopropylamine salt of $\mathrm{N}$-(phosphonomethyl) glycine and $52 \%(\mathrm{w} / \mathrm{v})$ polyoxyethyleneamine (as surfactant) which was obtained from Monsanto Company. A kit of malondialdehyde (MDA) was purchased from Biodiagnostic Co., Cairo, Egypt. All other chemicals were of analytical grade.

\section{Plant materials}

The leaves were collected from EUC plant grown in Aswan University outskirts. The plant was taxonomically identified to El-Hadidi and Boulos [11]. The leaves were naturally air-dried and extensive grounded into a fine powder utilizing a laboratory blender. $50 \mathrm{~g}$ of the leaf powder 
was soaked in $200 \mathrm{ml}$ of $100 \%$ methanol for $48 \mathrm{~h}$ with infrequent shaking, followed by filtration of the crude extract. The filtered extract was dried under vacuum at $40^{\circ} \mathrm{C}$ to obtain a semisolid mass of the methanolic crude extract.

\section{Analysis of plant extract scavenging activity}

Free radical scavenging activities of working solutions $(10-100 \mu \mathrm{g} / \mathrm{ml})$ of EUC crude extract were determined according to Shimada method [12,13]. 2 ml of 2,2-diphenyl-1-picrylhydrazyl (DPPH) solution $(0.1 \mathrm{mM})$ was combined with $1 \mathrm{ml}$ of plant extracts and another $1 \mathrm{ml}$ of ascorbic acid as antioxidant. The absorbance of the complex mixture was accurately determined at $517 \mathrm{~nm}$, after 30 min obscured. The percentage of the DPPH radical scavenging was calculated by applying the fundamental equation as given below

$$
\begin{gathered}
\text { Percentage inhibition of DPPH radical }=[(\text { Abs control-Abs sample }) / \\
\text { Abs control }] \times 100
\end{gathered}
$$

Determination of bioactive secondary metabolites and phytochemical screening using gas chromatography-mass spectrometry (GC-MS) analysis

Bioactive secondary metabolites, for example, total phenolics and flavonoids were calculated as described previously [14]. Agilent GC-MS is used for screening and detecting volatile bioactive compounds with an initial temperature of $120^{\circ} \mathrm{C}$ for the column oven. Standard temperature increased steadily by $5^{\circ} \mathrm{C} / \mathrm{min}$ to $200^{\circ} \mathrm{C}$ with holding 2 min and finally increased to $280^{\circ} \mathrm{C}\left(10^{\circ} \mathrm{C} / \mathrm{min}\right)$. Helium utilized as a carrier gas at a constant discharge rate of $1 \mathrm{ml} / \mathrm{min}$. The injector and indicator temperature steadily remained at $250^{\circ} \mathrm{C}$. The solvent delay was precisely $2 \mathrm{~min}$ and diluted samples of $1 \mathrm{ml}$ automatically injected with autosampler AS3000 intimately bound with GC in the split mode. EI mass spectra was gathered at $70 \mathrm{eV}$ ionization voltages over the scope of $\mathrm{m} / \mathrm{z} 40 \mathrm{e} 550$ in full output Mode. The ion source and transfer line temperatures were set at 200 and $250^{\circ} \mathrm{C}$, respectively. The active compounds were accurately distinguished by direct correlation of their retention times (RT) and mass spectra with those of NIST 11 Mass Spectral (2011) database.

\section{Animal ethical committee approval}

We declare that all facets of animal care and maintenance according to Aswan University code of standard practice for the proper care and practical use of experimental animals for scientific purposes were carefully followed. This includes a responsibility to safeguard and promote the welfare of animals used.

\section{Determination of the $\mathrm{LD}_{50}$ of EUC}

A gradual series of EUC extract dosed in a constant volume of $250 \mu \mathrm{l} / \mathrm{g}$ body weight was used to determine the effective dose that passes $50 \%$ of the tested animals within $96 \mathrm{~h}$. $\mathrm{LD}_{50}$ value of the crude extract was calculated according to the following equation $=0.2433 \mathrm{X}+0.4327$.

\section{Animal grouping and treatment}

Forty male adult Egyptian toads (B. regularis) weighing 65-70 g were randomly collected from Aswan Governorate, Egypt. The collected toads were laid down in plastic containers $(120 \mathrm{~cm} * 65 \mathrm{~cm} * 60 \mathrm{~cm})$ with a perforated coat to allow air circulation and maintained under standard laboratory and animal health welfare conditions. Room temperature was kept at $25^{\circ} \mathrm{C}$ with drinking water provided ad libitum. Experimental animals were orally given either RUP or EUC $(1 \mathrm{ml} / \mathrm{kg})$ for a period 21 days. Experimental groups were assembled into four identical groups (10 per group) as shown hereafter.

The first group (negative control [NC]): Animals were used as a NC group.

The second group (EUC): Animals orally treated with $0.2 \mathrm{mg} / \mathrm{g}$ of EUC extract $\left(1 / 20 \mathrm{LD}_{50}\right)$.

The third group (RUP): Animals orally treated with $8 \mathrm{mg} / \mathrm{kg}$ of RUP.

The fourth group (RUP+EUC): Animals treated with an equal dose of EUC extract $1 \mathrm{~h}$ earlier before RUP treatment.
Biochemical assays for the lipid peroxidation (LPO) measurements Malondialdehyde concentrations were measured in the liver tissues of all independent groups, expressed as nmol/g tissue, and measured as described by the manufacturer

\section{Microscopic examination}

Light microscopy

The liver tissues were fixed in 10\% neutral buffer formalin and implanted in paraffin. $5 \mu \mathrm{m}$ sections were prepared for Harris's hematoxylin and eosin stain, Mallory's triple stain, and periodic acid Schiff's technique $[15,16]$. Demonstration of the organ section to study the histological and histopathological alterations was performed under high-power light microscopic (Olympus BX43F, Tokyo163-0914, Japan). Images were analyzed using specific software (Olympus DP74 Tokyo 163-0914, Japan).

\section{Electron microscopy}

For ultrastructural examination, the samples processed, examined, and photographed in the Electron Microscopic Unit at Assiut University. Small pieces of the liver immediately immersed in phosphate-buffered $4 \mathrm{~F} 1 \mathrm{G}$ in $\mathrm{pH} 7.2$ for $3 \mathrm{~h}$ at $4^{\circ} \mathrm{C}$ after placed in $1 \% \mathrm{OsO}_{4}$ (Osmium tetroxide) at $4^{\circ} \mathrm{C}$ for $2 \mathrm{~h}$. Specimens were dehydrated in gradual ethanol series and then embedded in Epon-Araldite mixture in BEEM polyethylene capsules (Agar Scientific, UK). Ultrathin sections are about $50 \mathrm{~nm}$ obtained using the LKB ultramicrotome and caught on 200 copper grids. Grids were stained for $30 \mathrm{~min}$ with lead citrate and uranyl acetate. Coated grids were prepared for TEM electron microscope (Model 100 CXII equipped with CCD digital camera Model XR-41) at $80 \mathrm{KV}$.

\section{Quantitative reverse transcription-polymerase chain reaction (QRT-PCR)}

Expression of target genes, recombination-activating gene 1 (RAG1), CX Chemokine receptor type-4 (CXCR4), and cytochrome c oxidase subunit I (COX 1) in liver tissues was examined using QRT-PCR. Liver total RNA was isolated using Trizol $^{\circledR}$ according to the manufacturer's instructions (Madison, USA). $5 \mu \mathrm{g}$ of total RNA were converted into cDNA using a commercial kit as instructed. Genes were extracted from UniProtKB database https://www.uniprot.org/uniprot/and converted to DNA sequence using sequence manipulation Suite http://www. bioinformatics.org/sms2/rev_trans.html, and theprimerswere designed using Primer3 website http://bioinfo.ut.ee/primer3-0.4.0/. Primers were designed at Invitrogen (Invitrogen, USA) using the following sequence for RAG1, forward TTTGCAACAGCAGCAAAAAC- 3 and Reverse 5'-GCTCGGATCCAGATGAATGT-'3(accession number is A0A096XJM1_ SCLRE); COX1, forward 5'-TGCAGCGGGAATTACAATGC-' 3 and Reverse 5'-ACCTCTGGGTGTCCGAAAAATC-'3 (accessionnumber is A0A185A7B1_ SCLRE); and CXCR4, forward 5'-CCGATAAATATCGCCTGCAT-'3 and Reverse CCAGGCTAATAAACGCCAGA-3(accession number is A8CUC3_SCLRE). Gene expression of each gene was normalized to the 16S rRNA Forward 5'-AGGTCAAGGTGCAGCAAATG-' 3 and Reverse 5'-TGCTAAATCCGCCTTCCAAC-'3.

\section{Statistical analysis}

All the statistical analyses were performed by GraphPad Prism 6. Data were measured in triplicate and presented as mean \pm standard error deviation (SD). Statistical differences were analyzed using one-way ANOVA followed by the Student-Newman-Keuls t-test. A statistical significance was accepted at ${ }^{*} \mathrm{p}<0.05,{ }^{* *} \mathrm{p}<0.01$, and ${ }^{* * *} \mathrm{p}<0.001$.

\section{RESULTS}

\section{Analysis of plant extract scavenging activity}

The free radical scavenging activity of different concentrations from Eucalyptus methanolic crude extract was compared with that of AA using DPPH scavenging assay. The increase in the concentration of Eucalyptus methanolic extract enhanced the scavenging of DPPH (Fig. 1). The calculated values of $\mathrm{IC}_{50}$ were $48.45 \pm 0.17$ and $6.45 \pm 0.30 \mu \mathrm{g} / \mathrm{ml}$ for Eucalyptus crud extract and ascorbic acid, respectively (Fig. 1). 
Determination of bioactive secondary metabolites and phytochemical screening using GC-MS analysis

The EUC methanolic extract revealed rich contents of flavonoids approximately $453.67 \pm 36 \mathrm{mg} \mathrm{QE} / \mathrm{g}$ extract and polyphenols 329.12 $\pm 12.1 \mathrm{mg} \mathrm{GAE} / \mathrm{g}$ extract (Fig. 2).

The GC-MS analysis of the EUC methanolic extract identified 19 compounds, and the major bioactive compounds were hexadecanoic acid, methyl ester (47.77\%); octadecenoic acid, methyl ester (16.24\%);

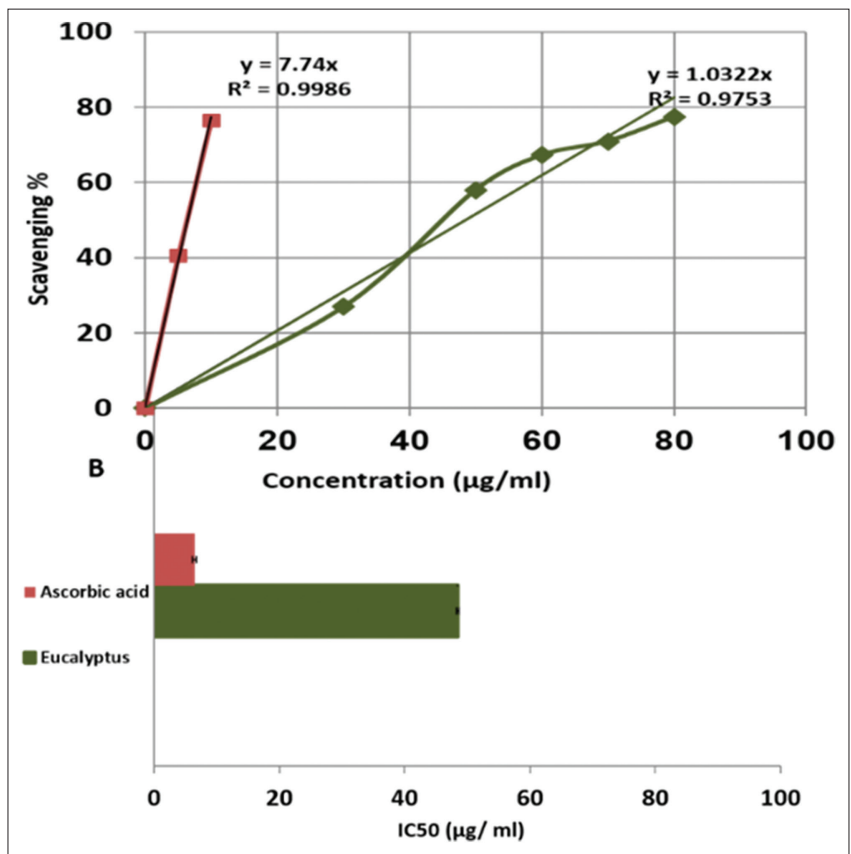

Fig. 1: 2, 2-Diphenyl-1-picrylhydrazyl radical scavenging activity of methanolic extract of Eucalyptus camaldulensis was set against quercetin and ascorbic acid

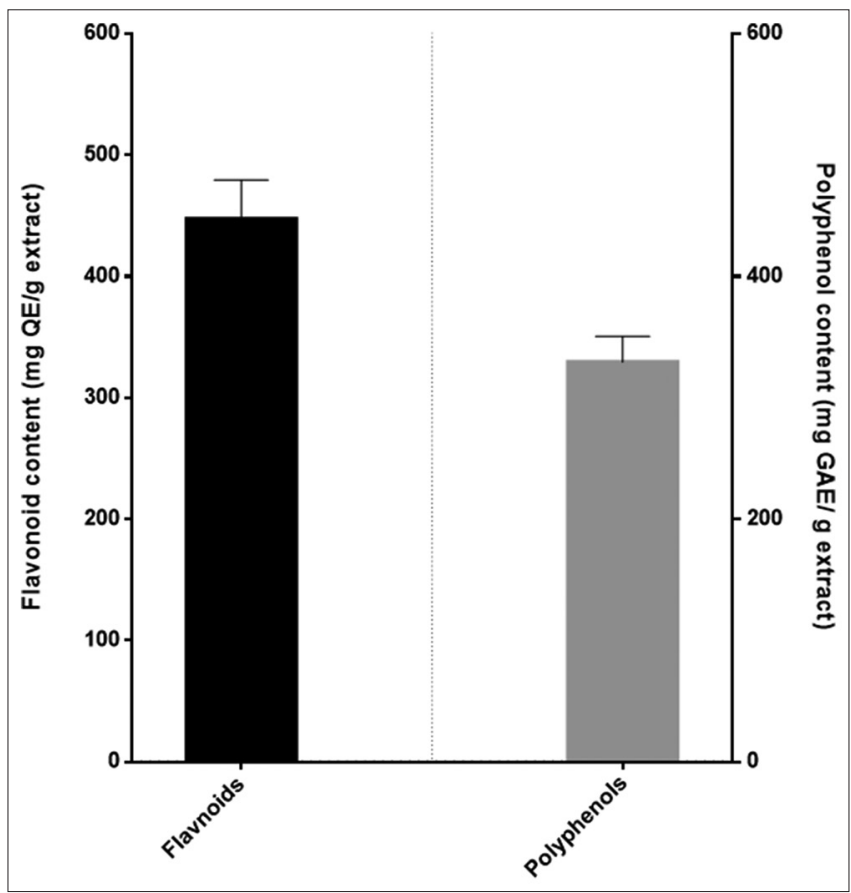

Fig. 2: Measurement of flavonoids and polyphenols.

Flavonoid content (mg QE/g extract) and polyphenol content (mg GAE/g extract) of the Eucalyptus camaldulensis $(\mathrm{n}=3)$ methyl stearate (5.77\%); and methyl tetradecanoate (4.19\%). Other data such as RT and peak area percentages (area \%) of these compounds are shown in Table 1.

\section{The LPO measurements}

Levels of MDA in the liver of RUP-treated frogs increased significantly when compared with the control group after 21 days of treatment $(\mathrm{p}<0.05)$. Treatment with EUC markedly antagonised RUP effects by attenuation of LPO and consequently reduced the MDA levels $(p<0.05)$ as shown in Fig. 3.

\section{Liver HE, collagen, and glycogen staining}

Liver sections of control and EUC-treated groups showed normal hepatic architecture (Fig. 4a and b). Histological studies demonstrated significant number of acini lined by the hepatic cells. In addition, narrow blood sinusoids (BS) and slightly considerable number of pigment granules (melanomacrophages [MMCs]) and the central veins $(\mathrm{CV})$ with conventional circular outline were identified. On the contrary, liver sections of RUP group revealed severe histopathological alterations (Fig. 4c). Veins and sinusoidal spaces were congested and

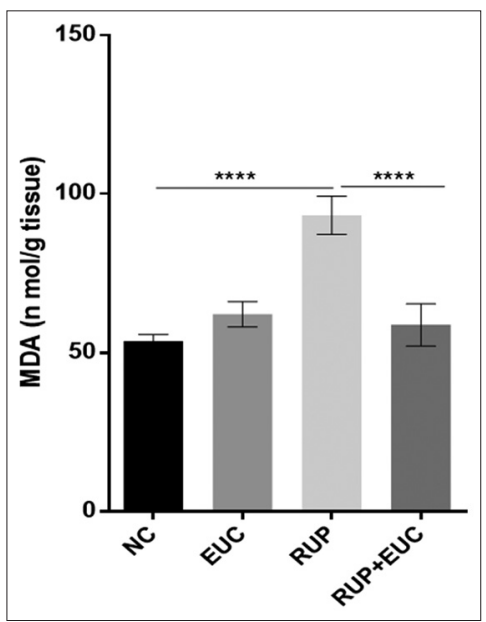

Fig. 3: Lipid peroxidation assay (LPO). Mean values of LPO (malondialdehyde) in the liver homogenates of control and treated groups $(n=8)$. Highly significant increase/decrease from the corresponding control ${ }^{* * *} \mathbf{p}<0.001$

Table 1: GC-MS analysis of the leaf methanolic extract of Eucalyptus camaldulensis

\begin{tabular}{llll}
\hline No & Compound name & RT & Area \% \\
\hline 1 & Butanamine, 4-(methoxydimethylsilyl) & 3.905 & 1.22 \\
2 & Silane, trimethyl (phenylmethoxy) & 4.237 & 0.58 \\
3 & Dioxolane, 2-butyl-2-methyl & 4.334 & 0.67 \\
4 & Butanoic acid, 2-methyl-, & 6.011 & 0.24 \\
& 2-methylpropyl ester & & \\
5 & Pentane, 2,2,3,4-tetramethyl- & 6.085 & 1.33 \\
6 & Decane & 6.217 & 1.7 \\
7 & Methyl tetradecanoate & 13.77 & 4.19 \\
8 & Nonadiyne & 15.892 & 0.95 \\
9 & Acetophenone & 16.036 & 1.66 \\
10 & Pentadecanoic acid, methyl ester & 16.551 & 3.32 \\
11 & Methyl tetradecanoate & 17.804 & 1.44 \\
12 & Hexadecenoic acid, methyl ester, (-Z) & 18.027 & 47.77 \\
13 & Benzene, 1,2,3-trimethyl- & 18.124 & 1.51 \\
14 & Benzoylheptanoic acid & 18.748 & 0.61 \\
15 & Pentadecanoic acid, methyl ester & 18.891 & 1.5 \\
16 & Benzene, (1-methylethyl)- & 19.183 & 1.05 \\
17 & Indolinol, 1-benzoyl- & 19.572 & 2.62 \\
18 & Octadecenoic acid, methyl ester & 20.853 & 16.24 \\
19 & Methyl stearate & 21.168 & 5.77 \\
\hline GC-MS: Gas chromatography-mass spectrometry & &
\end{tabular}


full of blood. The MMCs fused forming large globules together instantly seen in several liver areas. In addition, hepatic cells appeared with a strongly basophilic cytoplasm and pyknotic nuclei. Setting against the RUP group, liver sections of RUP+EUC-treated frogs showed normal histology to a broad extent. It conserved the majority of liver structure including hepatic cells, veins, and sinusoids with retaining substantial number of the pigment granules (Fig. 4d).
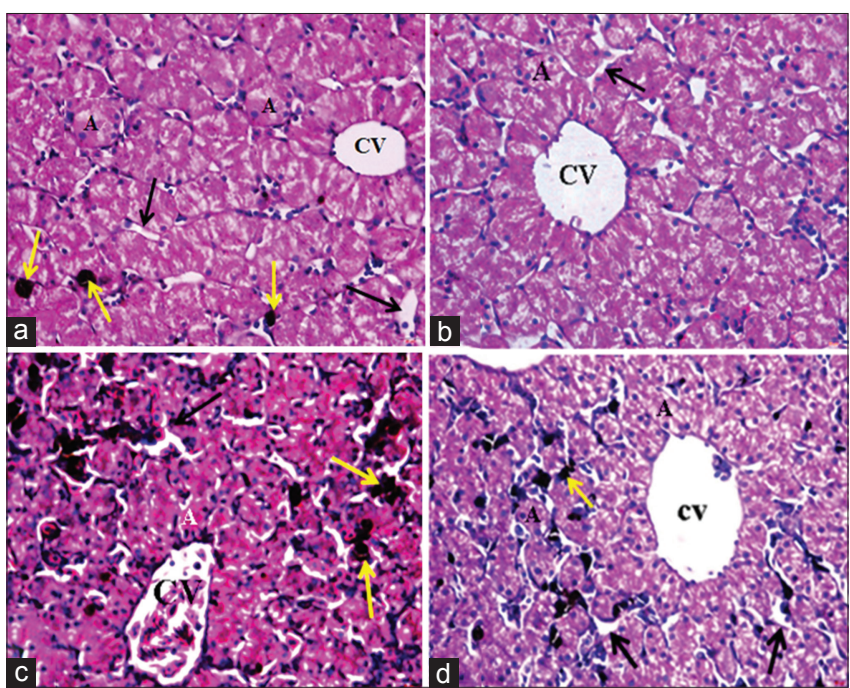

Fig. 4: Liver stained with hematoxylin and eosin. Control and treated liver showed normal histology when stained with hematoxylin and eosin stain ( $a$ and b) General morphology of toad liver architecture; hepatic acini (A), central veins (CV), blood sinusoids (BS) (black arrows), and pigments (yellow arrows); (c) Severe damage of the hepatic acini (A) which fused together forming syncytial masses. In addition, pigments fused together forming large globules (yellow arrows). The congested CV and BS (black arrow) was prominent.

(d) Normal appearance to somewhat of hepatic acini (A), CV, BS

(black arrows), and melanomacrophages (yellow arrows). Original magnification: $\times \mathbf{4 0 0}=\mathbf{5 0} \mu \mathrm{m}$.

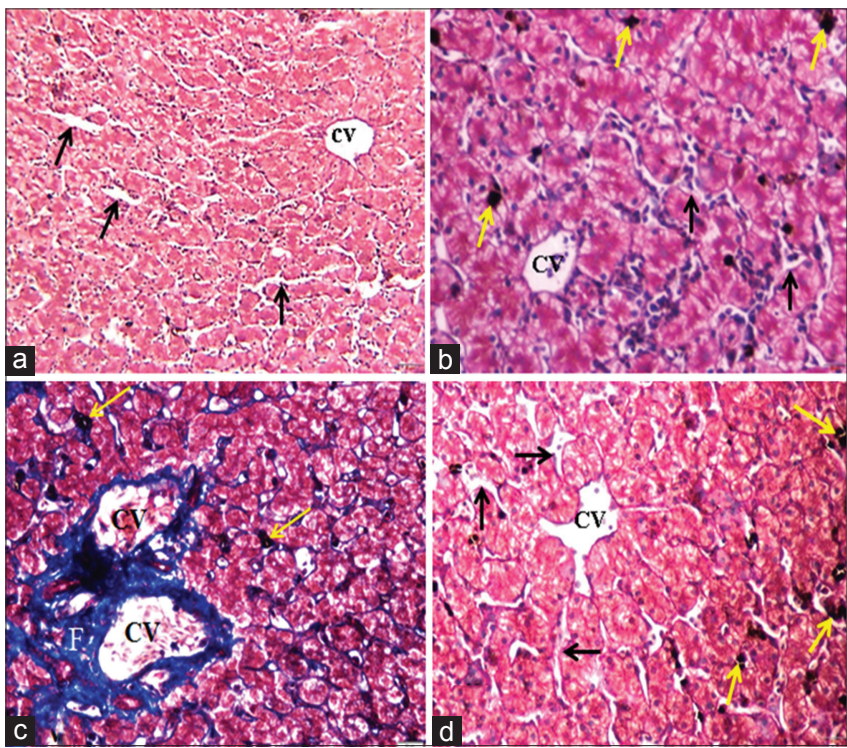

Fig. 5: Collagen fibers of the liver sections stained with Masson's trichrome stain. Control and treated liver stained with Masson's trichrome stain for collagen fibers. (a-d) Normal distribution of the collagenous fibers around the central veins $(\mathrm{CV})$ as well as the blood sinusoids (BS) (arrow). (c) An exuberant amount of the collagenous fibers $(F)$ around dilated $\mathrm{CV}$. Original magnification: $\times 400=50 \mu \mathrm{m}$
The liver sections of control and EUC-treated frogs were stained with Mallory's triple stain revealed normal distribution of collagen fibers as blue-colored stripes around the CV and BS (Fig. 5a and b). In RUP-treated frogs, collagen fibers increased massively (Fig. 5c) while markedly reduced in RUP+EUC-treated groups (Fig. 5d). In addition, treatment of EUC reverses the glycogen depletion that found in the RUP-treated group (Fig. 6d and c, respectively). In the control and EUC-treated group, considerable amount of glycogen granules in the liver sections of control was detected (Fig. 6a and b).

\section{Electron microscopy}

The liver micrographs of the control and EUC group showed normal histological structures (Fig. 7a and b). Liver cells typically appeared with oval to round nuclei delineated by a prominent nuclear envelopes and cytoplasm. Perinuclear region has much variety of well-defined organelles like mitochondria and rough endoplasmic reticulum (RER). In addition, non-living deutoplasm was appeared as glycogen particles. In contrast, the liver of the RUP group exhibited progressive pathological impairments such as pyknosis of the atrophied nuclei, advanced mitochondrial deterioration, and numerous lipid vacuoles (Fig. 7c). Comparing with the earlier group, electron micrograph of the RUP+EUC group showed that the hepatic cells retained their ultrastructural integrity for a great extent (Fig. 7d).

\section{Gene expression analysis}

We examined possible effects of RUP on gene expression of three genes named, respectively, (RAG1), CXCR4, and COX1 in the common Egyptian toad $B$. regularis. Relative expression analysis of qRT-PCR data revealed moderate differential expression among the different treatments. RAG1 was downregulated $8 \%$ in RUP-treated group and increased 3\% in other treated groups as shown in Fig. 8a, while CXCR4 was increased by $20 \%$ in the RUP-treated group and shows moderate change in the other groups (Fig. 8b). On the other hand, COX1 showed significant expression reduction, and it was about $43 \%$ and $25 \%$ of RUP-treated only or RUP+EUC-treated group, while its expression was increased about $10 \%$ in the only EUC-treated group (Fig. 8 c).

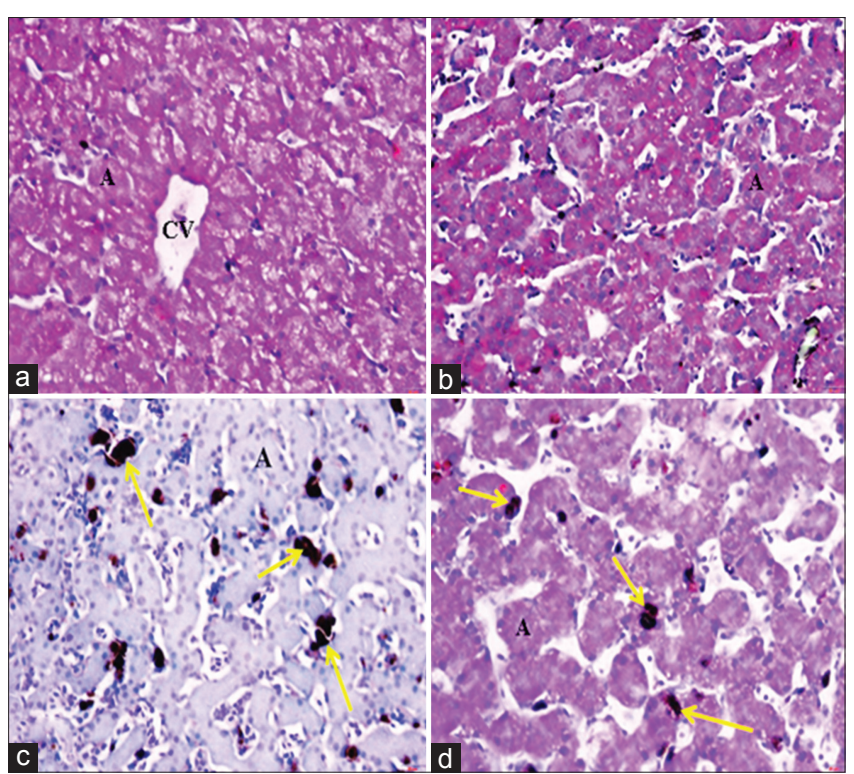

Fig. 6: Periodic acid Schiff's (PAS) - preparations of liver sections obtained from control and treated frogs. (a and b) Strong PAS reaction in the acini $(A)$ cells, stained with intense magenta color, indicating their richness of polysaccharides (specifically glycogen granules). (c) Complete loss of glycogen from the all cells of the acini (A) with melanomacrophages (yellow arrows). (d) Moderate PAS - reactivity in most of the acini (A) cells with low number of melanomacrophages (yellow arrows). Original magnification: $\times \mathbf{4 0 0}=\mathbf{5 0} \mu \mathrm{m}$ 


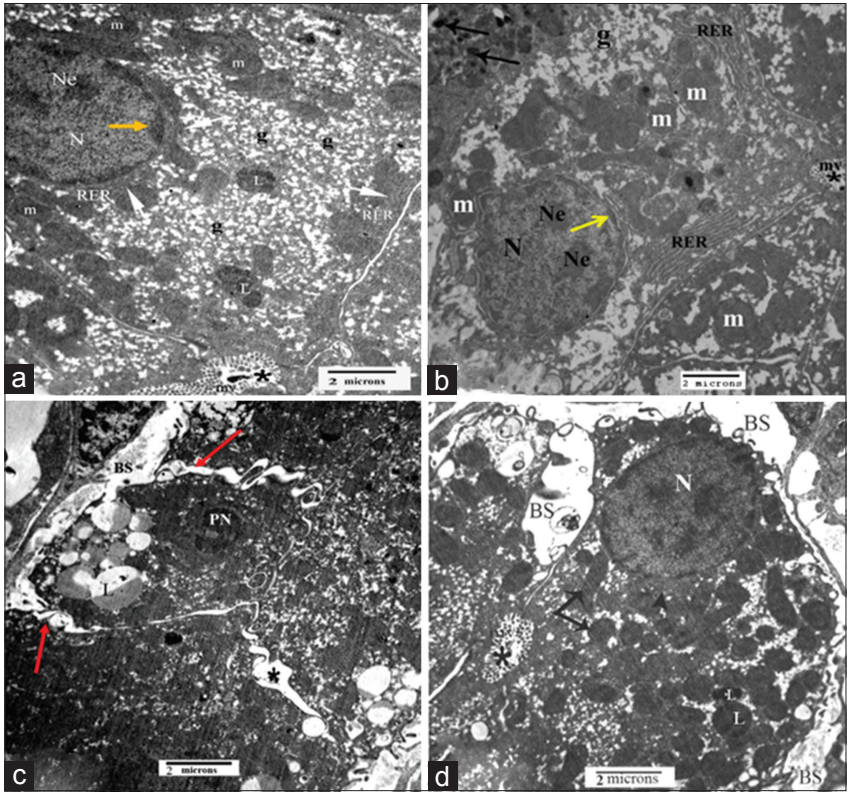

Fig. 7 Electron micrographs of liver sections of frogs. (control; a and EUC treated group; b) showing oval-to-rounded nucleus (N) with well-discernible nuclear envelope and chromatin particles (yellow arrows), prominent nucleoli ( $\mathrm{Ne}$ ), mitochondria (m), rough endoplasmic reticulum (RER) pointed to with white arrows, lysosomes (L), and glycogen particles (g). In addition, the bile canaliculus (star) observed with its microvilli (mv).

(c) RUP treated group showed marked dilatation between the plasma membranes (red arrows), bile canaliculus (star) without microvilli and congested blood sinusoids (BS) were observed. As well, distinct pyknotic features of the more atrophied nucleus

(PN) and large number of lipid vacuoles (L) were observed.

(d) RUP+EUC treated group showed rounded nucleus (N),

mitochondria (arrows), (RER) arrowhead, lysosomes (L), bile canaliculus (star) with inwardly projecting microvilli were demonstrated

\section{DISCUSSION}

Amphibians universally were considered effective bioindicators. Its sensitivity to environmental hazardous chemicals is extraordinary, particularly to herbicides which have been implicated as a main cause of subsidizing in a considerable decrease of amphibians [17]. Herbicides are always leading diverse effects on modern amphibians, especially, during their embryonic stages and on their growth rate, development, successful reproduction, and behavior [18]. Herbicides cause different harmful effects by generating free radicals, alteration of Redox, and antioxidant status $[19,20]$. Therefore, reactive oxygen species (ROS) may involve in the toxicity of RUP, herbicide-based glyphosate. As a result, several biochemical, histological, and immunological markers were extensively evaluated to better understand the mechanism of RUP-induced cytotoxicity.

Treatment of the Egyptian frog with RUP significantly elevates the liver MDA levels when opposed to control animals $(\mathrm{p}<0.05)$. Current data are comparable to other independent researchers who reported identical time-dependent depletion of GSH and accompanied by increased LPO production by RUP and glyphosate [21]. Moreover, others reported that excessive ROS severely damages the mitochondrial membrane and affects the cellular integrity through oxidation of lipids, proteins, and DNA [7].

Following chronic exposure to RUP, significant changes were found in the liver of treated frogs. We continuously observed severe vascular inflammation of veins and BS. In addition, the hepatocytes were shown strongly basophilic cytoplasm with pyknotic nuclei and a significant

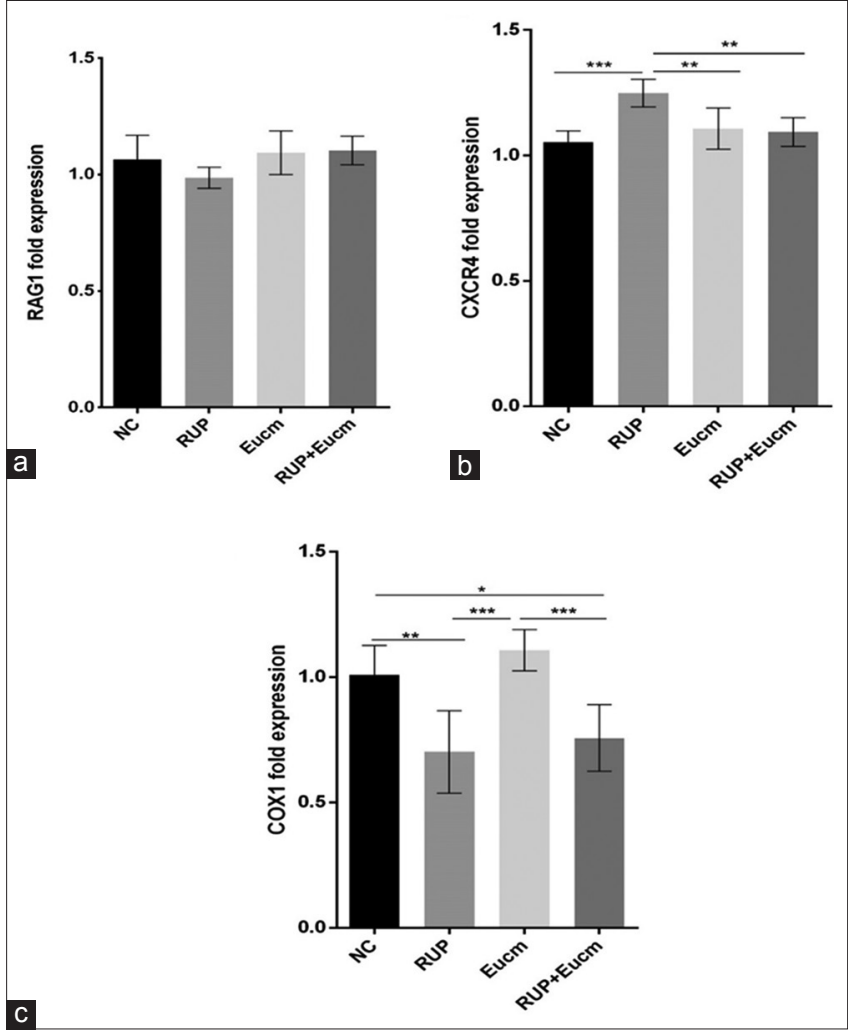

Fig. 8 Relative gene expression analysis. Relative gene expression of recombination-activating gene $1, \mathrm{CX}$ Chemokine receptor type-4, and cytochrome $c$ oxidase calibrated to the 16S rRNA gene $(n=6)$. Significant increase/decrease from the corresponding control represented as follow ${ }^{*} \mathrm{p}<0.05,{ }^{* *} \mathrm{p}<0.01$, and ${ }^{* * *} \mathrm{p}<0.001$

increase in the number of MMCs. These results indicate precisely to MMCs as a major player in detoxification of RUP and may play additional immunological aspects and engulfing of foreign bodies and eradicate possible infections [22]. Our direct observations were likewise comparable to data that demonstrated a marked increase in the number of MMCs in the liver of frogs exposed to insecticides [23]. In addition, we instantly noticed massive debris of collagenous fibers around the CV and BS. This accumulation is typically indicating hepatic fibrosis as an appropriate response to chronic liver injury that hallmarks by excessive deposition of extracellular matrix components [24].

Based on the current data, we assume that RUP can induce mitochondrial damage and inhibit mitochondrial respiration increasing the cytotoxic effects of ROS in the liver. We evaluate the activity of COX1 by measuring its gene expression. We noticed downregulation of the COX1 gene expression and reduced $43 \%$ and $25 \%$ in the RUP and RUP+EUC-treated groups, respectively. COX is the main regulator of oxidative phosphorylation (OxPhos) that regulates T-cell activation and proliferation through apoptosis [25]. Reduction in COX 1 expression may alter the bioenergetics of naïve T-cell, which relies on glucose oxidation through OxPhos and depends on this change in bioenergetics demands. These alterations would mount insufficient immune response that is required for detoxifying and eliminating the other invaders.

In addition, We assessed that expression level of RAG1; a gene encoded protein involved in activation of immunoglobulin V(D)J recombination and pre-assembly into $\mathrm{B}$ and $\mathrm{T}$ cells. The RAG1 gene is moderately affected by RUP treatment and was decreased about $8 \%$. RAG proteins are essential for the differentiation and survival of B- and T-cell; the deletion of RAGs in mouse impairs T- and B-cell maturation and consequently deletes the functional mature T- and B-cells of the immune system $[26,27]$. 
In $\mathrm{T}$ lymphocytes, the chemokine CXCL12 is the single ligand for the chemokine receptor CXCR4, together they control T-cell migration and activation of leukocytes and are thus involved in the recognition of immune cells at sites of damage and inflammation [28]. CXCR4 was also tested for its gene expression levels; we found an increment by $19 \%$ in the RUP-treated group. Its role in fine tuning of immune responses and the costimulatory signals was evidenced. These molecules recognize damage sites, attract T-cells, and redirect leukocyte migration among blood, lymph, and tissues [29]. In addition, increased CXCR4 indicates poor prognosis in liver fibrosis [30], as noticed here in the current study by the accumulation of collagenous fibers around specific areas of the liver.

We assumed that RUP mediates its toxic effects through the production of high levels of ROS which downregulate COX1, a metabolic checkpoint that regulates cell fate decisions during T-cell activation and differentiation. Tissue attempts to eliminate RUP toxicity and restore redox homeostasis by upregulating CXCR4 attracting much more MMCs to the injury sites. Melanin accumulates in the target areas and produces large patches of isolated MMCs cells and MMCs centers.

Treatment of frogs with EUC+RUP showed overall amelioration indicating high oxidation scavenging activity as shown by the MDA and DPPH assay. The majority of identified compounds previously known as bioactive compounds such as hexadecanoic acid and methyl ester, which detected to possess antioxidant, anti-inflammatory, and antimicrobial activities [31]. The linoleic acid (LA) is the major polyunsaturated fatty acid in the biosynthesis of arachidonic acid (AA) and some prostaglandins, leukotrienes, and thromboxane [32]. Esters of LA present in the EUC are the hexadecanoic acid methyl ester and octadecenoic acid methyl ester, which represent $64 \%$ of the overall identified compounds. Those active compounds were typically showed anti-inflammatory, anemiagenic, and hepatoprotective properties [33].

\section{CONCLUSION}

The current study represents a direct evidence for the adverse effects of RUP on the liver histology of the Egyptian toad at sublethal concentrations. Our data contribute positively to recognize the key role of the immune system in toxicological events of RUP. It is adequately demonstrated that despite the historical fact mentioned that absence of potential toxicity of glyphosate-based formulas. Contemporary data sufficiently indicate many direct and indirect changes accompanied with the sublethal dose. Changes in physiology and histology accumulate over long-term causing differential side effects and might transfer likely to man. The application of natural antagonists from local plants (e.g., EUC) can reduce the biological hazardous effects. Ultimately, we are emphasizing the importance of using native species, such as B. regularis, and at time assessing indigenous and regional problems.

\section{AUTHORS' CONTRIBUTION}

Awadalla EA and Mohamed A.A designed and performed experiments. They were involved in manuscript editing and finalization as well. Abdelsadik. A designed entire study project and contributed in experiment performing, finalization and implementation, manuscript editing, and finalization.

\section{CONFLICTS OF INTEREST}

The authors declare that they have no conflicts of interest.

\section{FUNDING AGENCIES}

Not applicable.

\section{REFERENCES}

1. Aktar MW, Sengupta D, Chowdhury A. Impact of pesticides use in agriculture: Their benefits and hazards. Interdiscip Toxicol 2009;2:1-2.

2. Dallegrave E, Mantese FD, Oliveira RT, Andrade AJ, Dalsenter PR, Langeloh A. Pre- and postnatal toxicity of the commercial glyphosate formulation in wistar rats. Arch Toxicol 2007;81:665-73.
3. Relyea RA. The lethal impacts of roundup and predatory stress on six species of north american tadpoles. Arch Environ Contam Toxicol 2005; 48:351-7.

4. MarlattVL, Martyniuk CJ. Biological responses to phenylurea herbicides in fish and amphibians: New directions for characterizing mechanisms of toxicity. Comp Biochem Physiol C Toxicol Pharmacol 2017; 194:9-21.

5. Krynak K, Burke D, Benard M. Landscape and water characteristics correlate with immune defense traits across Blanchard's cricket frog (Acris blanchardi) populations. Biol Conserv 2016;193:153-67.

6. Berger G, Graef F, Pallut B, Hoffmann J, Brühl C, Wagner N. How does changing pesticide usage over time affect migrating amphibians: A case study on the use of glyphosate-based herbicides in German agriculture over 20 years. Front Environ Sci 2018;6:6.

7. Mertens M, Höss S, Neumann G, Afzal J, Reichenbecher W. Glyphosate, a chelating agent-relevant for ecological risk assessment? Environ Sci Pollut Res Int 2018;25:5298-317.

8. Firenzuoli F, Gori L. Herbal medicine today: Clinical and research issues. Evid Based Complement Alternat Med 2007;4:37-40.

9. Qader K, Al-Saadi S, Al-Saadi T. Chemical composition of Myrtus communis L. (Myrtaceae) fruits. J Appl Life Sci Int 2017;12:1-8.

10. Mondal M, Khalequzzaman M. Toxicity of naturally occurring compounds of plant essential oil against Tribolium castaneum (Herbst). J Biol Sci 2010;10:10-7.

11. El-Hadidi N, Boulos L. The Street Trees of Egypt. Cairo: Cairo Press; 1988.

12. Shimada K, Fujikawa K, Yahara K, Nakamura T. Antioxidative properties of xanthan on the autoxidation of soybean oil in cyclodextrin emulsion. J Agric Food Chem 1992;40:945-8.

13. Fidrianny I, Choirunnisa A, Ruslan K. Comparison of five antioxidant assays for estimating antioxidant capacity from three Solanum sp. extracts. Asian J Pharm Clin Res 2016;9:123-8.

14. Dezsi Ș, Bădărău AS, Bischin C, Vodnar DC, Silaghi-Dumitrescu R, Gheldiu AM, et al. Antimicrobial and antioxidant activities and phenolic profile of Eucalyptus globulus labill. and Corymbia ficifolia (F. Muell.) K.D. Hill \& L.A.S. Johnson leaves. Molecules 2015;20:4720-34.

15. McManus JF. Histological demonstration of mucin after periodic acid. Nature 1946;158:202.

16. Konstantopoulos P, Doulamis IP, Tzani A, Korou ML, Agapitos E, Vlachos IS, et al. Metabolic effects of Crocus sativus and protective action against non-alcoholic fatty liver disease in diabetic rats. Biomed Rep 2017;6:513-8.

17. Hayes TB, Falso P, Gallipeau S, Stice M. The cause of global amphibian declines:Adevelopmentalendocrinologist'sperspective.JExpBiol2010; 213:921-33

18. Quaranta A, Bellantuono V, Cassano G, Lippe C. Why amphibians are more sensitive than mammals to xenobiotics. PLoS One 2009;4:e7699.

19. Goetz ME, Luch A. Reactive species: A cell damaging rout assisting to chemical carcinogens. Cancer Lett 2008;266:73-83.

20. Abdulmohsin H, Abu Raghif A, Manna M. The protective effects of Echinops heterophyllus aqueous extract against methotrexate-induced hepatotoxicity in rabbits. Asian J Pharm Clin Res 2019;12:384-90.

21. de Moura F, Brentegani K, Gemelli A, Sinhorin A, Sinhorin V. Oxidative stress in the hybrid fish jundiara (Leiarius marmoratus $\times$ Pseudoplatystoma reticulatum) exposed to Roundup Original. Chemosphere 2017;185:445-51.

22. Pérez-Iglesias JM, Franco-Belussi L, Moreno L, Tripole S, de Oliveira C, Natale GS. Effects of glyphosate on hepatic tissue evaluating melanomacrophages and erythrocytes responses in neotropical anuran Leptodactylus latinasus. Environ Sci Pollut Res Int 2016;23:9852-61.

23. Franco-Belussi L, Castrucci A, de Oliveira C. Responses of melanocytes and melanomacrophages of Eupemphix nattereri (Anura: Leiuperidae) to Nle4, D-Phe7- $\alpha$-melanocyte stimulating hormone and lipopolysaccharides. Zool 2013;116:316-24.

24. Yasui Y, Abe T, Kurosaki M, Higuchi M, Komiyama Y, Yoshida T, et al. Elastin fiber accumulation in liver correlates with the development of hepatocellular carcinoma. PLoS One 2016;11:e154558.

25. Tarasenko TN, Pacheco SE, Koenig MK, Gomez-Rodriguez J, Kapnick SM, Diaz F, et al. Cytochrome c oxidase activity is a metabolic checkpoint that regulates cell fate decisions during $\mathrm{T}$ cell activation and differentiation. Cell Metab 2017;25:1254-68.

26. Jiang N, Fan Y, Zhou Y, Liu W, Robert J, Zeng L. Rag1 and rag2 gene expressions identify lymphopoietic tissues in juvenile and adult Chinese giant salamander (Andrias davidianus). Dev Comp Immunol 2018; $87: 24-35$.

27. Van Horn SA, Johnson KM, Childs JM. Rheumatoid-nodule-like 
cutaneous granuloma associated with recombinase activating gene 1-deficient severe combined immunodeficiency: A rare case. J Cutan Pathol 2018;45:940-3.

28. Liekens S, Schols D, Hatse S. CXCL12-CXCR4 axis in angiogenesis, metastasis and stem cell mobilization. Curr Pharm Des 2010;16:3903-20.

29. Contento RL, Molon B, Boularan C, Pozzan T, Manes S, Marullo S, et al. CXCR4-CCR5: A couple modulating T cell functions. Proc Natl Acad Sci U S A 2008;105:10101-6.

30. Hong F, Tuyama A, Lee TF, Loke J, Agarwal R, Cheng X, et al. Hepatic stellate cells express functional CXCR4: Role in stromal cell-derived factor-1alpha-mediated stellate cell activation. Hepatology 2009;
49:2055-67

31. Alqahtani F, Aleanizy F, MahmoudA, Farshori N, Alfaraj R, Al-Sheddi E, et al. Chemical composition and antimicrobial, antioxidant, and antiinflammatory activities of Lepidium sativum seed oil. Saudi J Biol Sci 2018.

32. Shichiri M, Yoshida Y, Niki E. Unregulated Lipid Peroxidation in Neurological Dysfunction, in Omega-3 Fatty Acids in Brain and Neurological Health. Boston: Academic Press; 2014. p. 31-55.

33. Krishnamoorthy K, Subramaniam P. Phytochemical profiling of leaf, stem, and tuber parts of Solena amplexicaulis (Lam.) gandhi using GC-MS. Int Sch Res Notices 2014;2014:567409. 